\title{
MODULAR HOME OFF-SITE CONSTRUCTION PRODUCTION LINE IMPROVEMENT
}

\author{
Youyi Zhang ${ }^{1,4}$, Mana Moghadam ${ }^{2}$, and Mohamed Al-Hussein ${ }^{3}$ \\ ${ }^{1}$ MSc. Student, Department of Civil Engineering, University of Alberta \\ ${ }^{2}$ Product Development and R\&D Manager, Civeo, Edmonton \\ ${ }^{3}$ Professor, Department of Civil Engineering, University of Alberta \\ ${ }^{4}$ Corresponding author's e-mail: youyi@ualberta.ca
}

\begin{abstract}
Today modular and off-site construction practices are widely used as a novel approach to residential and commercial building construction. Although this approach is known for its high production efficiency and low material waste, manufacturers are facing the challenge of fully differentiating their modular construction procedures from the conventional construction approach. Manufacturers are thus seeking to continuously implement efficient methodologies to improve their production line effectiveness, thereby enhancing their market competitiveness.

This paper proposes a methodology enabling the modular manufacturer to overcome this challenge and increase their assembly line productivity by implementing building information modelling (BIM)-supported lean manufacturing concepts, with a particular focus on the importance of the upstream pre-assembly line. This technique was implemented on a case-study, a residential modular factory, and increased the production line productivity by implementing the Lean-assembly concept. This approach is supported by the information provided from an enhanced BIM model generated to deliver accurate resource quantity required at each assembly station.
\end{abstract}

\section{KEYWORDS}

Lean manufacturing, BIM, modular off-site construction, pre-fabrication

\section{INTRODUCTION}

Today modular off-site construction practices are widely used as a novel approach to residential and commercial building construction. This approach is known for its high production efficiency and low material waste. For the past years, more and more innovated technology and advance management concept has been introduced to the state-of-the-art modular construction manufacturing industry aiming to further elevate their competitiveness in the construction industry.

Lean concept as the irreplaceable enabler in automobile industry in the past decade has proven it outstanding ability to Haitao et al. (2009) to improve the production line efficiency for manufacturers. The methodology of targeting to eliminate the waste in respect of time, space, man-hour, material, tool and even human effort led lean manufacturer becomes to one of the core values that prelude the modular manufacturer construction evolution.Bo (2008) summarized that 
lean for manufacturing requires standardised, repetitive activities that can be measured and controlled. Yet, construction manufacturing products which tend to be highly customized and involve with dramatic complex activities become challenging.

This paper believes construction manufacturers are facing the challenge of fully differentiating their modular construction procedures from the conventional construction approach. By changing the mind set to construct modular home with manufacturing procedure from using conventional construction procedure, the gap to fully utilizing lean concept in construction from manufacturing can be levelled. The transformation to highly productive modular manufacturing requires lean thinking throughout the overall production flow assisted by BIM technology, visualization tool as well as simulation applications.

\section{CURRENT STATE OF MODULAR HOME OFF-SITE CONSTRUCTION}

The current state of modular home off-site construction can be described as stick build under a roof. There is permanent space for inventory storage on site, workers do not need to suffer the crucial weather and the equipment and tools are located in an assigned location. However, except the pre-assemble line for floor, wall and roof framing, as soon as the product becomes box, any value added to the box afterwards are following the same procedure as if the work is done out in the field. Non-value added activities are not being eliminated, work procedures does not been standardized, the methodology of how to reduce the waste in respect of material and labour is not developed. For example, in the case study that will be mentioned in this paper, sheathing installation is happening after the modular box is formed. The procedure requires cutting the sheathing to specific sizes, lifting the sheathing manually and climbing up and down to install the sheathing at different level. The issues that come with the above procedure are time consuming and waste generated activity, heavy physical demand work in ergonomic aspect, non-value added activity, respectively. Lean manufacturing could potentially provide the solution for these issues, and stop following the conventional construction thinking becomes to the key for the success of this revolution. Therefore, it is important to start putting effort into production process technology with customized lean manufacturing system to make it fit the uniqueness of construction process.

\section{Transformation challenges}

There is no doubt that the uniqueness of construction process is the barrier to transfer lean manufacturing to modular home manufacturing. Understand the speciality for both manufacturing and modular home construction is beneficial for creating a new system that combined with utilizing the common shared technology as well as innovating fresh ideas to fit the existing practice.

Industrial sector like automobile meet the "requirement" of operating with standardised working procedure and the necessity of having repetitive process enable the factory gaining the benefit of eliminating waste by lean application. The standardised and repetitive characteristic of general manufacturing work stations are usually able to follow the lean principle to become efficient on their assemble line. Andrea (2013) summarized the lean principle for manual assembly workstations design based on the following principles: continuous flow, lean machines simplicity, workplace organization, parts presentation, reconfigurability, product quality, maintainability, ease of access and ergonomics.

Consider the characteristic of modular construction manufacturing, the aforementioned lean principles is challenging because of couple of reasons. Firstly, modules are relatively larger scale 
products which can be harder to handle. The mobilization of a house compare with a car or equipment will not be the same. Secondly, the process flow for building a modular home compare with other manufacturing products can be entirely different. One of the special characters for construction is that there is specific precedence between activities. Roof cannot be erected before the walls are connected and supported by floor. Wall panel cannot close by sheathing and drywall before the wiring and plumbing is in place. More details will be discussed in the following session; however, it is important to understand that general manufacturing production flow is easier to control due to the fact of having less constrains on its precedence rules. Thirdly, the variation of the structure type, unstandardized working procedure and highly customized design becomes the largest impede to applying lean production with its full extension in modular construction manufacturing. It has been mentioned by Guillermo (2009), Bo (2008) and Haitao (2013) that the lack of repetitive in modular production makes the feasibility of applying lean production debatable. However, Haitao also argued in the same paper that despite of all the differences, "small quantities of many varieties under condition of low demand", which reflect the exact condition of modular construction today, was the soil that cultivated the lean production in automobile industry back then. Therefore, by knowing the challenges of dramatically improving the production efficiency for modular construction while applying lean production system can motivate manufacturers to seek for their customized methodology and make their transfer from manufacturing to construction feasible.

\section{Procedure to efficiency improvement}

The procedures has been implemented to a modular home manufacturer whose goal is to seeking a path to transfer from heavily manual work focused operation to semi-automated operation so that their weekly production can be increased by at least $20 \%$. It is critical to not increase the overall cost under the current competitive market. The following methodology for efficiency improvement in modular home construction includes a universal lean concept implementation as well as an enhanced lean concept implementation which is targeting the uniqueness of modular construction manufacturing.

\section{Basic lean concept}

\section{S implementation}

Known for its simple implementation and short waiting time for improvement, $5 \mathrm{~S}$ is selected to be the first step to initiate the whole efficiency improvement process for varies manufacturing.

In the case study, the $5 \mathrm{~S}$ implementation was suggested to the plant manager as the foundation of any further transformations. Plant manager not only agreed on but also committed to the changes. The lean tool rack was designed and stalled in place right away. Workers are required to clean up the working area at the last 30 minutes of every shift. During the shift, workers are also required to maintain a comfortable working environment at all time. The plant is operating with 10 hour shift every day, approximately 1 out of 10 hours has been contributed to the $5 \mathrm{~S}$ plan. Despite of an hour less of daily working hours, the plant was able to maintain their productivity with the $5 \mathrm{~S}$ application, meanwhile the plant has becoming clean and organized after three months of implementation. Wasted time because of finding the proper working tools and choosing the longer route to avoid the piled waste material is reduced. Potential safety hazards are also minimized under the positive working environment. 
The accomplishment of using $5 \mathrm{~S}$ in modular home manufacturing compare with in general manufacturing is very similar. The procedure of implementation does not require special considerations either. However, the improvement in potential hazards management and people's realization of lean thinking from the $5 \mathrm{~S}$ principle indicates its critical value to modular manufacturing specifically.

\section{On site observation}

On site observation is the enabler of the brain storming procedure on the plant. The goal is to finding the existing issues and looking for potential improvement opportunities, which were applied to the case manufacturer. A quick walk through with the plant manager for the whole factory acknowledged authors the overall production line process. The manager will be able to highlight the key issues in a macro level including the current plant productivity, targeted plant capacity, bottle neck activities, main operation barriers and limitations. In addition to the quick walk through, a more focused detail observation is as important. Learning the detail procedure of plant operation from the workers can be very beneficial as well. Workers from the case study factory were informed by manager ahead of time for the on-site observation and were told to prepare for the questions and suggestions, which give bonus to the observation result. Three A3 reports were created after the observation for the manufacturer and will be described in the following paragraph.

\section{A3 Report}

The outputs of the on-site observations are three separated A3 report for the case study manufacturing after a week of observation in the plant. The observation was mainly focus on the floor, wall and roof pre-assembly line which is the beginning of the main production line.

The floor panel that comes out from the floor assemble line has a lot of value add to it. Insulations, electrical wiring and plumbing are all installed to the panel with finished laminate or wood floor covered by full protection. Yet there are also potential improvements along the production line. The highlighted issues from the report including heavy lumber lifting which is a manual intensive activities. This ergonomic concern can be solved by designing proper jig table. It was mentioned in the report that a full assessment for designing a jig table is requirement before any decision making. Large amount of walking time is required for joists layout because there is no proper delivery machine support. Workers will need to walk between the joists pile and floor framing station repetitively which is time consuming activities. This non-value added activities could also be eliminate by using a jig table with a movable storage crossing bridge, refer to Figure 1. Another observation is that the pre-cut plates will be laid on the ground and nailed to the joists individually, refer to Figure 2. For a floor with more than 30 joists, the above process will be repeated 120 times for pre-cutting and 480 times for nailing which is deficient task compared to use open-web joists taking into account the extra time spent on creating notches later for plumbing and wiring. 


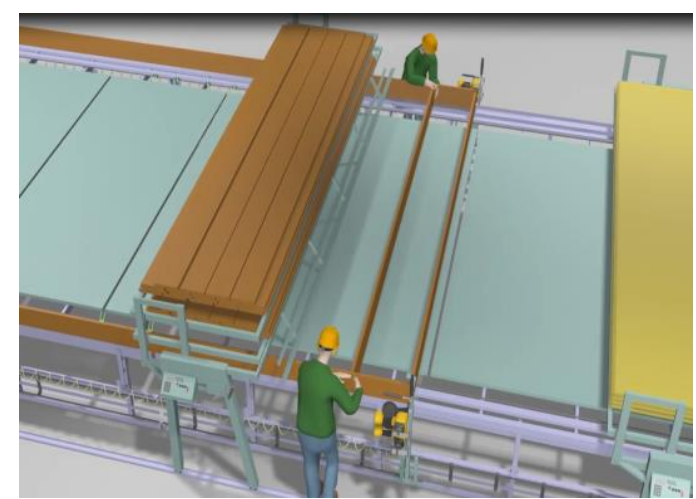

Figure 1: Proposed New Jig Table

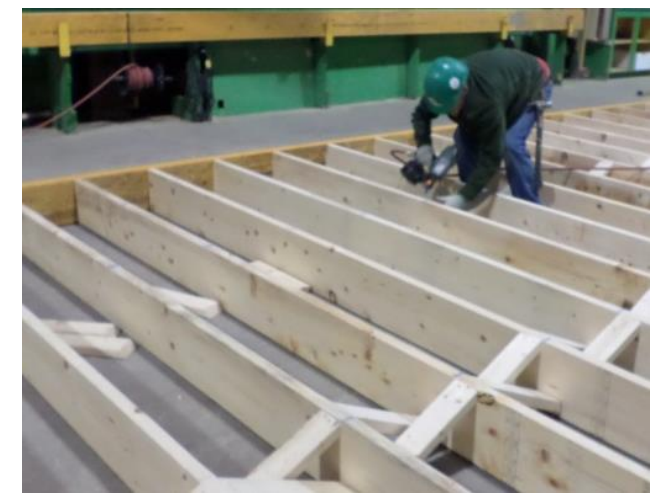

Figure 2: Crossing Wood Blocks Installation

The wall assemble line is also found to have large improvement potentials. Using crane to transfer the frame three times in the whole wall assemble line is wasting lots of valuable time. It takes 5 minutes in average to store one wall by crane. It is not only deficient but also has an impact on the quality of the wall frame due to the large deformation during the crane lifting. Suggestions are made to the factory to eliminate the non-value added activities as well as to improve the product quality efficiently. Using a butterfly machine to lift the wall frames from horizontal to vertical takes half of the time than using the crane, and the wall structure would also be protected. The wall can then be stored vertically by pushing down to the tracks from the butterfly machine.

Adding a new jig or a large butterfly machine into the existing system requires a big commitment from the plant. Both the top management and labours were involved in the decision making. The assessment for the changes is currently on going as this paper been rewritten and decision will be made based on the feasibility of the operation procedure and return of investment (ROI).

\section{Enhanced lean concept}

\section{Production line flow balancing}

Being able to design a production line that could "flow" throughout the process is the core value for modular manufacturing. Andrea (2013) mentioned that the continuous flow could eliminate the non-value added activities. Yet for a modular construction site where hundreds of activities are interrelated with each other, the contribution of a continues flow not only limited on 
eliminating the non-value added activities, but also help to secure the takt time at each work station, which has been a major issue for many manufacturing including the case study company. The reason why meeting the takt time at each station in modular construction manufacturing is more challenged than manufacturing had been addressed in the previous section. The solution for it is to start an innovated way of thinking. Instead of thinking what can be done to achieve lean production focusing on meeting lean first followed by finding the solution for it. This proactive attitude avoids the negative impact of saying no to the changes, in contrast, it encourages everyone in the plant to think and attribute.

To solve the transformation challenges the suggested solutions have been introduced to the manufacturer. The implementation test was successful yet further feasibility assessment is required. A detail validating process by using simulation model and real data analysis is beyond the scope of this paper and will be reported in a subsequent paper.

In general, modular home manufacturing plant are consist of pre-assemble line and main production line. Pre-assemble line is the main elements that differentiate the modular construction manufacturing from conventional construction. However, more work load pressure has been putting onto the main production process, which mostly operates as stick build under a roof. Refer to Table 1 which indicates the amount of space percentage taken by different plant section compare with the related value added to the product. The table clearly indicates the fact the main production line has been overly used whereas the pre-assemble line was not able to extend to its fully potential.

Table 1: Existing Procedure Utilization

\begin{tabular}{ccc}
\hline Regular Unit & Pre Assemble Line & $\begin{array}{c}\text { Main Assemble Line (Exclusive } \\
\text { Erection, Finishing, and } \\
\text { Inventory Section) }\end{array}$ \\
\hline Space\% & $37.5 \%$ & $12.0 \%$ \\
Trades\% & $29.1 \%$ & $41.8 \%$ \\
Utilization & $77.6 \%$ & $348.5 \%$ \\
\hline
\end{tabular}

On top of the unbalanced utilization, not able to meet the takt time at upstream main production line could tighten up the available space for downstream activities. As consequences, continuous flow is hard to achieve; workplace organization would not be simple due to the existing of multi-task stations; ease of access will be influenced because of the limited working area. To solve the problem that stop the production line been "lean", it is suggested to move the activities that involved with a lot of non-value added activities to the pre-assemble line. Activities like adding the sheathing, drywall, insulation and wiring require lots of walking movement around the module which is non-value added activity. Moving those value upfront at the wall framing pre-assemble line eliminate the waste of time from walking movement. It also creates an ergonomic environment for the worker since less heavy manual work is needed with the proper framing jig. The productivity when working in 2D motion compare with in 3D motion is dramatically improved. During the test run in the case study, a $72 \mathrm{ft}$ long exterior wall sheathing installation is finished within 20 minutes with two labours. The same work in current practice would require triple the times with the same man-power on the line. 
After relocate the specific activities to the pre-assemble line from downstream production line, the overall utilization of the plant is being balanced, the duration of problem stations at upstream main production line are shorten to its required takt time and the smooth out the following stations during the test run as a result. Refer to Table 2 for the summarized plant utilization for the test. The utilization for pre-assemble line increase to over $100 \%$ from close to $80 \%$ by releasing the pressure at downstream production line by more than $100 \%$.

\section{Table 2: Test Procedure Utilization}

\begin{tabular}{ccc}
\hline Test Unit & Pre Assemble Line & $\begin{array}{c}\text { Main Assemble Line } \\
\text { (Exclusive Erection, Finishing, } \\
\text { and Inventory Section) }\end{array}$ \\
\hline Space\% & $37.5 \%$ & $12.0 \%$ \\
Trades\% & $40.0 \%$ & $30.9 \%$ \\
Utilization & $106.7 \%$ & $257.6 \%$ \\
\hline
\end{tabular}

\section{BIM supported lean implementation}

The down side for shifting activities to the pre-assemble line is the possibility of over stress the beginning of the production line. More importantly, with more operation happening at early stage, the rework percentage could also increase potentially along the main production line. Therefore, it is critical to create a sub-production flow in the pre-assemble line and using the prefabrication concept to prepare the material as a sub-product before it goes to the pre-assemble line. It will be more efficient to produce the sub-product during pre-fabricate process than to prepare it on the pre-assemble line where varies activities need to be done. A typical example from the case study is as follow. Wall framing operation needs to layout footer, header, studs and special opening framing structure. In the existing process, framer will receive a wall framing layout as shown in Figure 3 and making the measurements before framing it. It is obvious that the opening components would requires extra effort from the framer. Extra cutting, measuring and nailing process brings the variation to production line therefore stop the flow of the process.
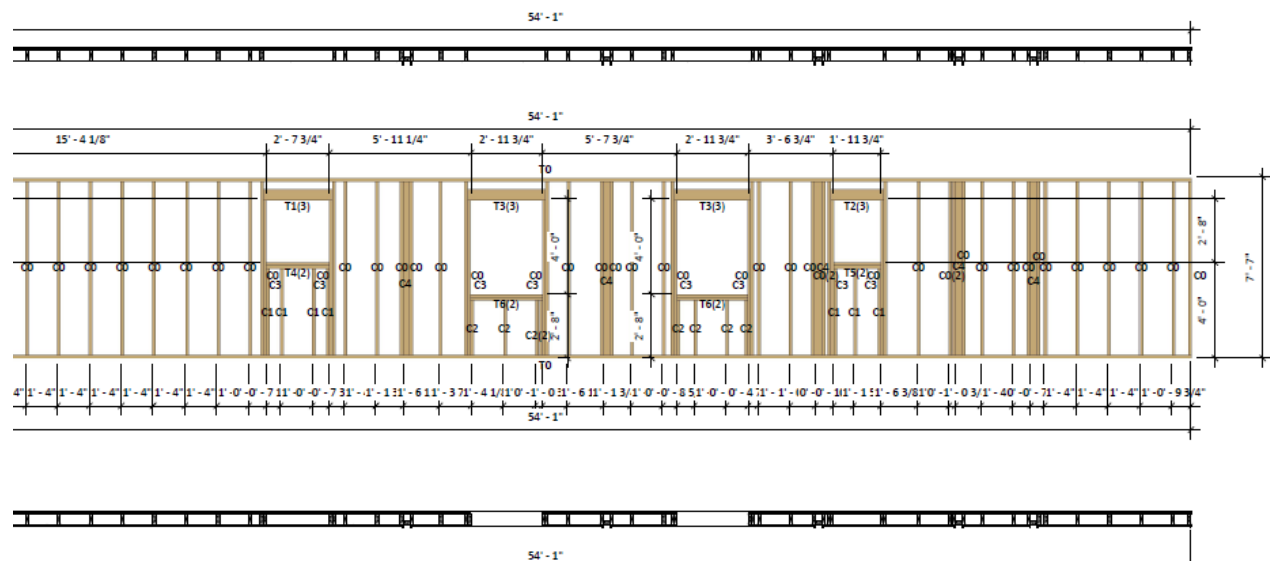

Figure 3: Wall Layout Drawing for Framer

The application of BIM in lean implementation plays an irreplaceable rule to help conquering the barrier of low level standardization with large scale product in modular construction 
manufacturing. Liu (2014) states in his research that BIM technology could provide accurate scheduling for wall panel installation based on specified criteria. The utilization of detailed and accurate information from construction software like Revit will extend to its full potential by using the BIM technology. One of the benefits from using BIM in this paper is to be able to generate a special information output from Revit model to support the pre-fabrication process. As mentioned in the previous paragraph, the opening components framing disturb the overall production line flow, however by pre-fabricate the components framing separately, the variation will be eliminated. BIM technology would be able to extract the exact information needed for component framing to ensure the efficiency and accuracy during the pre-fabrication process. A new separate drawing for components process adjusts was created; refer to Figure 4 for the cut list and drawings which will be used for pre-fabrication in the future. The information was extract from engineered model and the computerized process ensures the accuracy of the output. On the production line, the output helps to eliminate the manual figuring time and provide workers a straight forward and accurate drawing to precede the task.

\begin{tabular}{|c|c|c|c|}
\hline Label & Type & Count & Length \\
\hline C3 & $2 \times 6$ & 2 & $6^{\prime}-61 / 2^{\prime \prime}$ \\
\hline $\mathrm{CO}$ & $2 \times 6$ & 2 & $7^{\prime}-4^{\prime \prime}$ \\
\hline
\end{tabular}

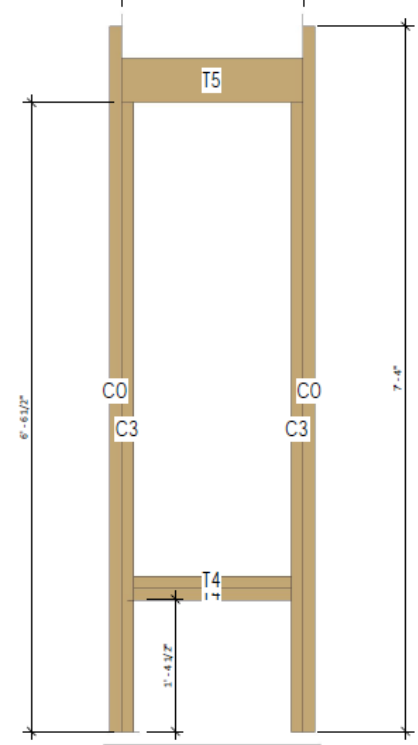

\begin{tabular}{|c|c|c|c|}
\hline Label & Type & Count & Length \\
\hline $\mathrm{T} 4$ & $2 \times 6$ & 2 & $1^{\prime}-73 / 4 "$ \\
\hline T5 & $2 \times 6$ & 3 & $1^{\prime}-103 / 4 "$ \\
\hline
\end{tabular}

Figure 4: Component Drawings

\section{Conclusion}

Lean production system has brought a successful transformation to modern manufacturing. Innovated technologies lead a qualitative shifting in wide variety industries for the past decade whereas the construction field is comparatively stable in its construction process. It is a big step to start thinking manufacturing houses, buildings, trailers etc., and to bring in the lean production into the construction manufacturing will further improve the factory capability. However, the current practice is limited on a management level, which is to use lean management tool and concept without putting enough effort on changing technology and way of thinking in actual construction process. The modular construction manufacturer is trying to adjust lean application to fit their needs, however it is important to be proactive and be innovated in adjust their production line into lean production.

The case study in this paper adjusted their process to fit the lean production and have starting to see primary improvement on their plant. By knowing the challenges of applying lean to 
modular home construction process, the plant managers were commitment to keep an open minded attitude towards the construction process aiming to standardize the work flow, downsizing the scale of the products and creating a new working precedence. From $5 \mathrm{~S}$ implementation to on-site observation, follow by production line flow balancing supported by BIM technology, the journey towards efficiency improvement can be universal. The methodology of adding more value upfront and focusing on pre-fabrication to produce subproducts can be the way to fit modular construction with lean production.

This research indicates the important role of lean production in modular manufacturing and discuss the reason of why this industry has not be able to use the system to its full extend. A proactive way of thinking which is to adjust the process to meet the needs of lean production will help the manufacturing to further improve their production line.

The proposed methodology in this paper has only been primarily studied based on historical data and a simple test run. Properly applying value stream map (VSM) and simulation in the feasibility study can be extremely help for the validation. Equipment and tools support on the production line also plays a key role in production line continues flow. Further study with interaction of construction process, equipment support and BIM technology will elevate the value of lean production system in modular home manufacturers.

\section{Acknowledgments}

The authors are sincerely grateful for the support from the case study modular home manufacturer offering their commitment for lean production implementation. Hexu Liu's technical support on BIM application is also greatly appreciated. We also want to thank to Jonathan Tomalty and Claire Kelly for their technical editing.

\section{References}

Hexu, Liu., Zhen, Lei., Hong Xian, Li., Mohamed, Al-Hussein. (2014). An automatic scheduling approach: building information modeling-based on-site scheduling for panelized construction. Construction Research Congress 2014 CASCE 2014 1478, 1478-1487.

Jørgensen, B., \& Emmitt, S. (2008). Lost in transition: the transfer of lean manufacturing to construction. Engineering, Construction and Architectural Management, 15(4), 383-398. http://doi.org/10.1108/09699980810886874

Lešková, A. (2013). Principles of lean production to designing. Annals of Faculty Engineering Hunedoara-International Journal of Engineering. Tome XI-Fascicule2 (ISSN 1584-2665), 31-37.

Velarde, G. J., Saloni, D. E., Dyk, H. Van, \& Giunta, M. (2009). Process flow improvement proposal using lean manufacturing philosophy and simulation techniques on a modular home manufacturer 1 Housing Market. Lean Construction Journal, 58, 77-93. 
Yu, H., Al-Hussein, M., Al-Jibouri, S., \& Telyas, A. (2011). Lean Transformation in a Modular Building Company: A Case for Implementation. Journal of Management in Engineering, (January), 77. http://doi.org/10.1061/(ASCE)ME.1943-5479.0000115

Yu, H., Tweed, T., Al-Hussein, M., \& Nasseri, R. (2009). Development of Lean Model for House Construction Using Value Stream Mapping. Journal of Construction Engineering and Management, 135(8), 782-790. http://doi.org/10.1061/(ASCE)07339364(2009)135:8(782) 